\title{
O jornalismo como tradução: fabulação narrativa e imaginário social
}

\author{
Gislene da Silva e Rosana de Lima Soares
}

Resumo: A proposta deste trabalho é articular dois campos aparentemente desconexos, os estudos de jornalismo e de tradução. Tem entre seus objetivos demonstrar possibilidades que ultrapassem a visão hegemônica de que o jornalismo mostra fatos cotidianos para aqueles que não os vivenciaram e que a tradução linguística traduz textos originais para os que não podem decodificá-los, ambos os processos afeitos ao modo fiel, objetivo e veraz. Tais visões compartilham a crença em certas dicotomias, como a separação entre verdade e linguagem, referencialidade e ficcionalidade, realidade e fantasia, fato e relato. Busca-se, desse modo, questionar a tradição da objetividade jornalística e da fidelidade ao texto por meio da assunção do caráter narrativo desses discursos e das marcas culturais neles presentes e das implicações disso no imaginário social.

Palavras-chave: jornalismo; tradução; discurso; narrativa; imaginário

Abstract: Journalism as translation: narrative fable and social imaginary - This paper proposes to link together two seemingly unrelated fields, journalism and translation studies. One of its objectives is to demonstrate possibilities that go beyond the traditional view that journalism translates everyday facts for those who did not experience them, that linguistic translation interprets original texts for those who cannot decode them, and that the mode of expression of both these processes is reliable, objective and truthful. These views share a belief in certain dichotomies, such as the separation between truth and language, referentiality and fictionality, reality and fantasy, fact and narrative. Thus, our aim is to question the tradition of journalistic objectivity and textual fidelity by assuming the narrative character of these discourses and their cultural aspects, and the implications of this for the social imaginary.

Keywords: journalism; translation; discourse; narrative; imaginary 
Repetir repetir - até ficar diferente. Repetir é um dom do estilo.

Manoel de Barros

\section{Texto, discurso, lealdade}

Este artigo articula dois campos aparentemente desconexos - os estudos de jornalismo e os estudos de tradução - e tem como um de seus objetivos demonstrar possibilidades que ultrapassem a visão hegemônica de que o jornalismo mostra fatos cotidianos para aqueles que não os vivenciaram em tempo real - tradução esta realizada de modo fiel, objetivo e veraz - e que a tradução linguística traduz textos originais para aqueles incapazes de decodificá-los em suas línguas estrangeiras - e, portanto, também de modo fiel, objetivo e veraz. Tais visões compartilham a crença em certas dicotomias que, ao longo da história do pensamento ocidental, desdobram-se em debates no campo da filosofia, da antropologia, da história, da literatura e das artes, dentre elas a separação entre verdade e linguagem, referencialidade e ficcionalidade, realidade e fantasia, fato e relato. No caso do jornalismo, os acontecimentos traduzidos se realizariam em outro lugar que não o discurso; no caso da tradução, os conteúdos traduzidos poderiam ser reproduzidos de modo simétrico.

Em ambos podemos identificar a noção de um "texto-fonte" (os fatos ou os textos originais) em relação ao qual haveria um compromisso com a acuidade do processo tradutório e a verossimilhança em seu resultado final, representado pelo texto traduzido. No caso do jornalismo, mais do que no da tradução - cuja materialidade discursiva já obriga a uma percepção de que, mesmo no caso da tradução linguística, não há um grau zero de onde partem as interpretações - notamos nesta visão hegemônica um saudosismo pela origem (o fato antes do relato, o acontecimento antes da linguagem), como se ao jornalismo fosse possível apreender o real tal qual, no seu esforço de aprisionar o presente. Tal concepção desconsidera um postulado há muito reconhecido nos estudos literários ou cinematográficos, e só mais recentemente considerado pelos poucos estudos sobre discurso jornalístico: o de que, afinal, tudo é tradução, pois o (re)escrito nunca é original - o que vemos são camadas discursivas que se desdobram em outras, de modo infindável, a exemplo da metáfora, evocada por Barthes, da "teia de aranha" que envolve o sujeito em seu discurso, do qual aquele seria, simultaneamente, produto e produtor:

Texto quer dizer Tecido; mas enquanto até aqui esse tecido foi sempre tomado por um produto, por um véu todo acabado, por trás do qual se mantém, mais ou menos oculto, o sentido (a verdade), nós acentuamos agora no tecido, a ideia gerativa de que o texto se faz, se trabalhar através de um entrelaçamento perpétuo; perdido neste tecido - nessa textura - o sujeito se desfaz nele, qual uma aranha que se dissolvesse ela mesma nas secreções construtivas de sua teia. Se gostássemos dos neologismos, poderíamos definir a teoria do texto como uma hifologia (hyphos é o tecido e a teia da aranha) (BARTHES, 1996, p. 83). 
A noção de texto é aqui referida de modo amplo - não apenas em sentido linguístico, mas como qualquer manifestação discursiva, seja verbal, seja visual, seja audiovisual. Desse modo, o texto é tomado como artefato verbal e como evento cultural. Para Barthes, “o texto é assim definido não como uma linha de palavras a produzir um sentido único [...], mas como um espaço de dimensões múltiplas, onde se casam e se contestam escrituras variadas, das quais nenhuma é original" (1988, p. 68). Ou seja, "o texto é um tecido de citações, saídas dos mil focos da cultura. [...] o escritor só pode imitar um gesto sempre anterior, jamais original; seu único poder está em mesclar as escrituras, em fazê-las contrariarem-se umas pelas outras, de modo a nunca se apoiar em apenas uma delas" (BARTHES, 1988, p. 69).

No campo do discurso (cf. BAKHTIN, 1997), ao contrário da possibilidade de estabelecimento de um princípio, não haveria um começo e um final, mas sim o entremeio ${ }^{1}$, lugar de desdobramentos incessantes, espaço permanentemente atualizado pelo leitor: "A realidade mais essencial é a mais escondida, não se situando nem na ausência do discurso, nem no explícito deste, mas no entremeio de sua latência, necessitando, portanto, de uma escuta ou leitura particular a fim de o revelar a si mesmo" (DOSSE, 1993, p. 336). Da necessidade de construir narrativas representativas de nossas subjetividades e pertencimentos, deriva o desejo de verdade (autenticidade, legitimidade, fidelidade) que vemos presente na produção jornalística, esquecendo-se de que, justamente por estar à deriva, o desejo é sempre desejo de outra coisa: ao chegarmos a ele, já é de outro lugar que falamos. Nas palavras de Deleuze, aproximamo-nos da perspectiva que postula a não anterioridade do real à linguagem: "A linguagem é um imenso há, na terceira pessoa, ou seja, o oposto da pessoa: uma linguagem intensiva, que constitui seu estilo" (DELEUZE, 1992, p. 143).

A esse respeito, um interessante paradoxo se explicita: o jornalismo, ao mesmo tempo que se pretende objetivo e imparcial, realiza todo o tempo um trabalho de tradução dos fatos em relatos. Ao contrário do acesso à verdade e à representação fiel da realidade, é um processo de descontinuidades que se inscreve no fazer jornalístico, encontrando, assim, ecos com o campo de estudos da tradução, observando-se que a tradução de um texto específico para outra língua geralmente desdobra-se em camadas de transposições. Deleuze e Guattari, ao tratarem das relações entre verdade e linguagem, reconhecem, para contestá-la, a impossível busca do jornalismo em compreender o caos:

Os jornais, as notícias, procedem por redundância, pelo fato de nos dizerem o que é 'necessário' pensar, reter, esperar etc. A linguagem não é informativa nem comunicativa, não é comunicação de informação, mas - o que é bastante diferente - transmissão de palavras de ordem, seja de um enunciado a um outro, seja no interior de cada enunciado, uma vez que o enunciado realiza um ato e que o ato se realiza no enunciado (DELEUZE; GUATTARI, 1997, p. 16).

1 Algumas das articulações estabelecidas entre discurso e história poderiam ser aplicadas ao jornalismo, especialmente na relação entre fatos e relatos: "Há de sempre criarmos uma diferenciação entre fatos e discursos. Não ao final do processo, pois para o historiador não será possível enxergar tal diferenciação no resultado obtido. Essa simbiose entre fato e discurso se dá no fazer-se. Seria imperativo, portanto, voltarmo-nos às ruínas iniciais, aos vestígios do entremeio e ao leve fantasma discursivo para podemos rastrear essas diferenças" (BAPTISTA, 2009, p. 17). 
Se o enunciado realiza um ato e o ato nele se realiza, o pressuposto de que haveria um momento inicial (um fato ou um texto) sobre o qual estabelecer o processo tradutório não se sustenta, posto que a ideia de tradução pressupõe, em todo caso, a noção de cultura em suas imbricações com o imaginário social. O fato, depois de acontecido, é sempre imaginado - traduzido. A literatura e o cinema proporcionam narrativas emblemáticas que constituem nosso imaginário, tornando-nos capazes de ficcionalizar relatos representativos de nós mesmos (SOARES, 2011). Sobre essa questão, Calligaris nos oferece uma visada original ao tratar do lugar que as "ficções" ocupam em nossa formação, apontando pelo menos dois aspectos. O primeiro diz respeito ao fato de a ficção apresentar a diversidade do mundo e constituir um repertório do possível: "No meio das diferenças particulares entre grupos, ela inventa experiências singulares que revelam a humanidade que é comum a todos, protagonistas e leitores. A ficção de uma vida diferente da minha me ajuda a descobrir o que há de humano em mim". Esta seria sua "mágica". O segundo aponta o que vimos tentando estabelecer ao tomarmos o jornalismo como tradução:

Há uma outra ideia, menos comum, segundo a qual a vida da gente pode (e talvez deva) ser vivida como uma narração. Não tanto para que ela se transforme num roteiro mirabolante, mas para que nosso cotidiano (por humilde e banal que seja) assuma uma relevância e uma intensidade que o tornem digno de ser vivido (CALLIGARIS, 2007).

Na perspectiva apresentada, as dicotomias iniciais se desfazem, diluindo a oposição entre verdade e linguagem, realidade e fantasia, pois o que temos são fabulações narrativas tecendo imaginários sociais, especialmente se tomarmos os discursos midiáticos como lugar privilegiado para tal articulação. Estabelecidas as premissas, uma indagação se faz premente: por que, afinal, o campo do jornalismo tangencia essas questões sem jamais parecer ultrapassálas? Talvez porque um de seus princípios fundamentais seja, justamente, considerar-se como lugar de organização da realidade, estabelecimento do senso comum e reiteração da ordem social. Ao se definir uma instância que traduz a realidade para aqueles que não podem vê-la (em sentido literal ou figurado), o jornalismo oblitera parte de sua natureza: assim como a tradução, é prática linguageira e, por isso mesmo, produção incansável de discursos sobre discursos (SOARES, 2010). Desse modo, o texto jornalístico, assim como o texto traduzido, não é verdadeiro nem falso; é um texto outro, que guarda traços - vestígios - dos acontecimentos.

Se o texto jornalístico é uma forma de tradução dos fatos, insere-se, portanto, no campo da "tradução cultural" e dos modos de construção simbólica da sociedade. Buscando contribuir com esse debate, há pesquisas brasileiras que se dedicam a estudar textos do jornalismo impresso informativo partindo das diferenças na abordagem jornalística sobre um mesmo fato quando das transposições das notícias de uma cultura de um país para outro. ${ }^{2}$ A prática da tradução nas redações e a difusão de notícias recebidas de agências internacionais colocam-se como preocupações iniciais de tais estudos.

2 No texto opinativo esse tipo de abordagem já é aceito, hegemonicamente. 
Segundo Zipser, pioneira nas investigações sobre as interfaces tradução-jornalismo ${ }^{3}$, nos jornais e nas revistas há matérias assumidamente traduzidas, nas quais se reserva ao autor/tradutor o crédito do trabalho e outras que, tendo sido traduzidas a partir das informações de agências ou de outros veículos de comunicação, aparecem sem assinatura (ZIPSER, 2002, p. 17). Em sua avaliação, prevaleceriam no ambiente do jornalismo duas concepções de tradução: uma mais voltada à letra e, portanto, assinada, e outra mais ampla, que concebe o texto traduzido primeiramente como insumo para ser trabalhado por outros profissionais, até se transformar em notícia. Zipser se pergunta se a tradução de matérias jornalísticas, realizada segundo critérios de fidelidade ao texto-fonte representa, ela mesma, um texto jornalístico. Ela desconfia que não, já que

uma tradução "fiel" ao texto-fonte e, por conseguinte, à cultura de partida não atenderia necessariamente às exigências do veículo e do público a que se destinam. A tradução no ambiente jornalístico, portanto, não poderia atender unicamente aos critérios de fidelidade à letra do texto-fonte, mas teria de levar em conta, igualmente, uma série de fatores que caracterizam o texto jornalístico como tal (ZIPSER, 2002, p. 6).

Essa tradução fiel ao texto serviria para a elaboração de outro texto (a tradução do fato a ser noticiado) com base na perspectiva da cultura destinatária da notícia. Portanto, a notícia apresentada ao público em diferentes culturas pode ser considerada tradução desse fato noticioso, no sentido de representação cultural.

O crivo de seu argumento se dá no paralelismo que faz entre o entendimento comum da tradução como mera transcodificação do texto jornalístico como expressão objetiva da realidade: "Assim como para a tradução já não se pode mais pensar numa acepção de transcodificação desvinculada da questão cultural, também para o jornalismo não se pode pensar na tradução de fatos sem a devida referência à cultura local" (ZIPSER, 2002, p. 12). Por isso, Zipser opta por trabalhar com o conceito de tradução como "representação cultural" e orienta pesquisas que buscam marcas culturais em textos jornalísticos, comparando publicações da imprensa brasileira e de outros países no tratamento de um mesmo acontecimento noticioso. Esses estudos interdisciplinares entre os campos da tradução e do jornalismo investigam temas, personagens, cenários, léxicos, redes semânticas, modalidades retóricas e construções narrativas no discurso noticioso. Tomam a questão do papel exercido pela linguagem e pela cultura na construção e na tradução de fatos noticiosos, especialmente aqueles que atravessam fronteiras geográficas e culturais ${ }^{4}$. Como base central, Zipser se fundamenta na interseção entre o trabalho

3 Diversas dissertações e teses têm sido desenvolvidas nessa direção no grupo de pesquisa Tradução e Cultura (Trac), coordenado pela profa. dra. Meta Zipser, do Programa de Pós-Graduação em Estudos da Tradução da Universidade Federal de Santa Catarina (UFSC), abordagem que, a nosso ver, merece ser investigada também no âmbito das mídias e, mais especificamente, do jornalismo.

4 Entre as pesquisas, uma analisa a tradução e a narratividade jornalística no caso do 11 de setembro em The New York Times e Folha Online, com interesse na tradução das manchetes (POLCHLOPECK, 2011); outras procuram identificar as diferentes marcas culturais em revistas multilíngues como National Geographic; revistas de bordo bilíngues; ou na comparação entre revistas nacionais e internacionais. 
de Christiane Nord ${ }^{5}$ - em seu modelo linguístico-textual voltado à tradução, contemplando desde a compreensão do texto-fonte até a função do texto traduzido em vista da cultura do destinatário - e de Frank Esser ${ }^{6}$ - em seu modelo pluriestratificado integrado que sistematiza vários fatores de influência na formação da produção noticiosa publicada.

Nord trabalha com o conceito de loyalität, lealdade ao destinatário, para diferenciá-lo do conceito de treue, fidelidade ao texto-fonte. Prevalece aqui a perspectiva da tradução como um processo prospectivo, direcionado para o destinatário, para o texto-meta, mais do que como ação retrospectiva, voltada para o texto-fonte (NORD apud ZIPSER, 2002, p. 39), já que o próprio tradutor torna-se leitor do texto a ser traduzido: "O leitor é sempre prospectivo, pensado à frente do fazer tradutório e jornalístico; afinal, o leitor é o responsável por realizar a função do texto e atribuir sentido para a sua leitura, através dessas marcas culturais" (POLCHLOPECK, 2001, p. 23). Desse modo, a "tradução jornalística" não se faz com base no texto original, mas de um fato que desencadeia diferentes traduções (angulações e enfoques) para a representação da notícia.

Zipser recorre a Nord para discutir, no caso do jornalismo, a noção bastante difundida de que os fatos noticiados são a própria realidade acontecida. Sabemos que ainda tem muita força esse entendimento de que o acontecimento é o fato que acontece na realidade, e ao jornalismo caberia a tarefa de colocar-se como mediador no ato de trazer esse acontecimento exterior para a interioridade do texto, dando-Ihe o destaque pertinente a seu grau de interesse e importância diante de determinado público. O texto jornalístico é tomado constantemente como transparente, estabelecendo uma distinção entre discurso e referente impensável nos estudos de discurso, em que a linguagem se coloca como opaca (SOARES, 2010). Estão aí as concepções de verdade e de correspondência entre textos e relatos, ou seja, uma visão realista (e instrumental) da linguagem.

Em geral, nas teorias sobre o jornalismo, ainda é central o fundamento de fidelidade do jornalista aos acontecimentos, observados juntamente os fundamentos de neutralidade e imparcialidade. Sabemos que em sua prática o jornalismo constitui-se como exercício profissional a partir do momento em que constrói um discurso ético que prevê a separação da opinião da informação; a supressão das discussões ideológicas por um discurso de neutralidade; a troca da persuasão pela busca da verdade; e a crescente importância do texto escrito de modo direto, claro e conciso, tornando hegemônicas as buscas pela objetividade, pela verdade, pela transposição dos fatos em relatos objetivos (PONTES; SILVA, 2010, p.52). A ideia de verdade fundada no referente justificaria distinção desta da prática profissional e, por correspondência, a sustentação de sua referência teórica.

5 Pesquisadora na Escola de Tradução e Interpretação da Universidade de Heidelberg (Alemanha), desenvolve modelos teóricos aplicados aos estudos da tradução que rompem com a visão tradicional desta como transposição linguística, inserindo os debates no campo mais amplo da tradução cultural implicada nesses processos.

6 Frank Esser estudou jornalismo em Londres (Inglaterra) e fez mestrado e doutorado na Johannes GutembergUniversität de Mainz (Alemanha). Sua tese foi publicada como o livro Die Kräfte hinter den Schlagzelein. Englischer und deutscher journalismus im Vergeleich [As forças por trás das manchetes: comparação entre o jornalismo inglês e o alemão]. Munchen: Verlag Albert GmbH Freiburg, 1998. 
Daí a crítica de Zipser às teorias do jornalismo, à presença de uma noção de tradução transcodificada e fiel ao fato.

Na interseção entre tradução e jornalismo, Zipser recorre principalmente a Esser, que possibilitou o estabelecimento de uma interface entre esses campos por meio de uma perspectiva cultural. Para Zipser, Esser subordina o estudo do jornalismo a uma série de condicionantes que o retiram de uma esfera ideal para colocá-lo ao lado de todas as outras manifestações discursivas na sociedade, descartando a visão de uma produção de sentido desvinculada da esfera social e da noção de cultura. Já é sabido que a notícia publicada resulta de um conjunto amplo de ações, tomadas por diferentes atores (TRAQUINA, 2004; SOUSA, 2002). É desse conjunto de ações, influências e poderes que se faz a notícia, o acontecimento noticioso a partir de ocorrências da vida, políticas e cotidianas, que por necessidade ou vontade são produzidas e consumidas (SILVA; SOARES, 2011).

Ainda em contraposição à perspectiva realista, encontramos nos estudos sobre narratividade jornalística mais questionamentos sobre a fidelidade ao real versus a construção de outra realidade nas notícias ou, ainda, sobre a impossibilidade de existência de uma realidade fora do discurso. Como observa Winch (1997), o discurso ético e profissional que visa uma relação ideal e especular entre texto e acontecimento passa a ser referencial de credibilidade e, consequentemente, institucionaliza a retórica da verdade. Assim como o positivismo defende, na pesquisa, a não interferência do sujeito na análise do objeto, o jornalista deve primar por não interferir nos fatos. É sabido que a preocupação referencial consolida a institucionalização do jornalismo. Porém, há reflexões do campo acadêmico que enfrentam essa convenção, inclusive trabalhados isolados dentro do próprio campo do jornalismo. E são os estudos sobre narrativa, e suas implicações na configuração do imaginário social, um dos principais investimentos para problematizar a hegemonia da referencialidade, com crítica enfática sobre o conceito de objetividade jornalística, afirmando que "o jornalismo é uma narrativa. Mesmo que narre elementos não ficcionais, ele organiza os fatos sob o formato de uma história e apresenta traços que identificam qual tipo de história está contando" (PONTES; SILVA, 2010, p. 53). Faz-se, portanto, como fabulação, conjunto de várias traduções entremeadas pelos discursos.

\section{Tradição, tradução e mediação}

Se, no momento da tradução, o tradutor deve se pautar pelo conhecimento que tem de seu leitor e pelo entendimento que nele deseja provocar, na hora da escrita do texto jornalístico também o jornalista deve se orientar pelo conhecimento que tem do público. O trabalho de Zipser nos ajuda a pensar os acontecimentos noticiosos que transitam de um lugar ao outro a partir do entendimento de que esses textos não se limitam à tradução de textos-fontes, como os vindos de agências e publicados como traduzidos. A hipótese de Zipser é que a visão de tradução como transcodificação, fiel à letra, não é suficiente para que o texto traduzido se caracterize como jornalístico. Com isso, ela abre a discussão para um conceito ampliado de tradução no jornalismo. 
O fato de a tradução ser um ato-comunicativo-em situação, voltado a um leitor final, prospectivo, faz do processo tradutório um ato marcado pelas referências culturais do contexto do qual o leitor-destinatário participa, uma vez que a tradução, segundo Nord, não ocorre somente ao nível do código, mas primordialmente no nível da cultura na qual o leitor está inserido (ZIPSER; POLCHLOPECK, 2009, p. 13).

Desse modo, o texto traduzido, bem como o texto jornalístico, volta-se ao outro que busca interpelar, constituindo-o no interior de sua narrativa e na relação eu-outro.

Interessa-nos, nesse momento, a definição da escrita do texto jornalístico como sendo uma tradução prospectiva do fato noticioso por excelência, uma vez que o acontecimento noticioso dá origem ao texto jornalístico, que, resultante de diversas ações, concretiza-se no momento de sua recepção pelo leitor (ZIPSER, 2002, p. 40). Por isso, a notícia, apresentada ao público pela imprensa em diferentes culturas $^{7}$, deve ser considerada a tradução do fato noticioso, no sentido de uma representação cultural: "[...] afirmamos que as diferentes leituras que fazemos acerca de um mesmo fato representam diferentes 'traduções' do mesmo, pois os processos constitutivos da elaboração da notícia se aproximam daqueles utilizados para a tradução" (ZIPSER; POLCHLOPECK, 2009, p. 13).

Portanto, no contexto das afinidades entre tradução e jornalismo, a transcodificação isenta seria para a tradução o que a neutralidade representa para o jornalismo. "Entretanto, considerar a possibilidade de que existam textos neutros e imparciais significa desconsiderar a linguagem como manifestação cultural, resultando na sua desvinculação como produto de um meio social e como processo formador de sentido" (ZIPSER; POLCHLOPECK, 2007). As autoras tratam da tentativa, por parte do tradutor-jornalista, de aproximar o fato de um leitor cultural ou geograficamente distante dele. Zipser está pensando a tradução na imprensa que noticia fatos internacionais, observando que os textos de diferentes veículos traduzem um mesmo fato, mas cada um a partir da perspectiva da cultura destinatária da notícia8: "Não haveria um texto de partida a servir de base para o texto da notícia, mas sim uma cultura de partida, expressa na forma como cada cultura enxerga o fato a ser noticiado" (ZIPSER, 2002, p. 159). É a partir daí que a pesquisadora investe na busca pelas marcas culturais.

Outra maneira de lidar com tais marcas é pensar em marcas contextuais, como sugerido no método "análise de cobertura jornalística" (SILVA; MAIA, 2011), quando propõe que as coberturas configuram um mesmo acontecimento social em diferentes acontecimentos jornalísticos, tratando de sistematizar as marcas de apuração, as marcas da composição e disposição da notícia nas páginas do veículo e as marcas contextuais dessa produção noticiosa. As marcas culturais, portanto, estão presentes nos textos jornalísticos,

7 Estamos tratando das culturas modernas, ambiência em que se configurou este jornalismo que temos hoje, em especial o modelo norte-americano e seus adeptos.

8 Zipser compara textos das revistas Der Spiegel e Veja sobre o mesmo fato noticioso, de caráter supranacional na imprensa internacional, cronologicamente equivalentes - os dez anos da queda do muro de Berlim, de novembro de 1989 a novembro de 1999. 
levando-nos a aproximar o jornalista da figura do tradutor, realizando uma espécie de "tradução cultural" nos moldes daquela apontada por Zipser e caracterizando-se, assim, como uma das formas narrativas voltadas à fabulação do cotidiano. O chamado "fato jornalístico" seria, portanto, tecido no entremeio dessas narrativas, sempre provisório e contextual, traduzido nos interstícios da cultura. Além disso, estabelece um complexo jogo de sobreposições em que o leitor, construído pelo texto no ato mesmo da leitura (ECO, 1994), interage com o autor e traduz o texto tantas vezes quantas forem as leituras empreendidas.

Partindo do pressuposto de que a recepção de notícias vivencia o jornalismo de maneiras diversas e tomando os movimentos de codificação e decodificação pensados como hipóteses por Hall (2005), consideramos que leitores ou telespectadores assumem posições a partir das quais a decodificação se constrói: posição hegemônica-dominante, quando se apropriam do sentido conotado; código negociado, quando conferem lugar privilegiado às definições dominantes dos acontecimentos, mas aplicadas às suas próprias regras e condições locais; e ainda quando decodificam as notícias de maneira contrária, dentro de algum referencial alternativo (HALL, 2005, p. 377-380).

Em vários de seus trabalhos, nos anos 1980, Hall procurou compreender as relações das mídias com cultura, linguagem e ideologia. Para o autor, as mídias (a) atuariam na construção seletiva do conhecimento social pelo qual percebemos as realidades vividas por outros e, assim, construiríamos imaginariamente um mundo inteligível; (b) proveriam um inventário constante de léxicos, estilos de vida e ideologias objetivadas, classificariam e ordenariam os diferentes tipos de conhecimento social, providenciando contextos referenciais que contribuem para dar sentido ao mundo; (c) e, além disso, organizariam essa classificação seletiva, produzindo consensos e legitimidades (apud SOUSA, p. 151). De acordo com Hall, deparamo-nos, então, com um falso dilema: com os processos de mundialização da cultura, pensamos que a identidade vai acabar de um modo ou de outro - ou retornando às suas raízes, ou desaparecendo através da assimilação e da homogeneização. Mas é justamente a "tradução" que se coloca como outra possibilidade (HALL, 2000, p.88), justamente por engendrar movimentos de hibridizações e mestiçagens.

Ao tratar do conceito de "tradução cultural", Hall (1996) apresenta sua teoria da articulação. Para ele essa palavra reveste-se de dois significados: articular significa em inglês, bem como em português, proferir e expressar uma ideia ou raciocínio, num sentido de construção na linguagem, de discurso, de comunicar-se bem (dizemos de uma pessoa que fala bem que ela é articulada). Mas também significa que duas partes distintas estão conectadas (como dizemos de um ônibus articulado), mas não necessariamente precisariam estar ligadas uma à outra. As duas partes conectadas por meio de um elo específico podem ser quebradas, separadas, divididas. Uma articulação é, assim, a forma de conexão que pode constituir uma unidade de dois elementos diferentes sob certas condições. É um elo que não é necessário, determinante, absoluto ou essencial todo o tempo para aqueles elementos relacionados e, dessa forma, um elo contingente, que pode ser desfeito. 
Sob que circunstâncias, então, pode se estabelecer uma conexão? Hall aponta como exemplo dessa definição a questão do discurso. A chamada "unidade" do discurso é de fato a articulação de distintos elementos que podem ser rearticulados de formas variadas porque não possuem necessariamente um sentido de pertença uns aos outros. A unidade que importa é o elo, o laço, a ligação entre esse discurso articulado e as forças sociais com as quais ele pode - mas não necessariamente precisa -, em certas circunstâncias históricas, estar conectado. Uma teoria da articulação é tanto um caminho para entender como elementos ideológicos surgem, em certas condições, para se agrupar em um discurso, quanto um caminho para perguntar como eles se tornam ou não articulados, em conjunturas específicas, para certos sujeitos políticos. A teoria da articulação, para Hall, pergunta como uma ideologia descobre seu sujeito mais do que como um sujeito pensa os pensamentos necessários e inevitáveis que pertencem a ela; pensa como uma ideologia fortalece as pessoas, capacitando-as a começar a dotar de sentido sua situação histórica, sem reduzir essas formas de inteligibilidade a suas condições específicas (HALL, 1996).

O conceito de "tradução cultural", para o autor, reveste-se desse aspecto ao mesmo tempo coeso e fluido presente na noção de articulação. Traduzir (fatos, textos) seria, portanto, rearticular (separar, reunir) as diversas partes de uma cultura. É justamente esse processo que o jornalismo, apoiado na retórica de objetividade e imparcialidade, pretende camuflar e elidir. Ao fazê-lo, perde de vista sua potência como acontecimento discursivo capaz de articular, de outros modos, elementos antes dispersos, traduzindo-os e recriando-os, dotando-os de novos sentidos sociais. Por outro caminho, Martín-Barbero elabora o conceito de mediação como alternativa para pensarmos as formas de tradução presentes nas narrativas jornalísticas:

Por isso, em vez de fazer a pesquisa partir da análise das lógicas de produção e recepção, para depois procurar suas relações de imbricação ou enfrentamento, propomos partir das mediações, isto é, dos lugares dos quais provêm as construções que delimitam e configuram a materialidade social e a expressividade cultural das mídias (MARTíN-BARBERO, 1997, p. 292).

Tal noção, que propõe o estudo das mídias em sua materialidade discursiva e não nos polos tradicionalmente isolados de "produção" e "recepção", conduz-nos a um dos pontos nodais do artigo: superar com mais vigor a tradição da objetividade jornalística e da fidelidade ao texto por meio da assunção do caráter narrativo desses discursos e das marcas culturais neles presentes. Pensar tais marcas culturais nos permite, como passo adiante na proposta de Zipser, considerar as diferenças na abordagem jornalística sobre um mesmo fato dentro de uma mesma cultura. Por tudo isso, os estudos da tradução, no entendimento aqui explicitado, desafiam o jornalismo a pensar-se, ainda uma vez, não como transcrição literal dos fatos e sim como tradução cultural que se refaz a cada escrita e a cada leitura, inscrevendo diariamente, em suas fabulações narrativas, velhos e novos imaginários sociais. 
Gislene da Silva é professora do Programa de PósGraduação em Jornalismo da Universidade Federal de Santa Catarina e doutora em Ciências Sociais/Antropologia pela Pontifícia Universidade Católica de São Paulo - PUC / SP).

gislenedasilva@gmail.com

Rosana de Lima Soares é professora do Programa de Pós-Graduação em Meios e Processos Audiovisuais da Universidade de São Paulo - USP e doutora em Ciências da Comunicação pela USP.

rosanasoares@gmail.com

\section{Referências}

BAKHTIN, Mikhail. Os gêneros do discurso - estética da comunicação verbal. São Paulo: Martins Fontes, 1997.

BAPTISTA, Thomas A. A narrativa simbólica do cinema e a representação do real na "história". (Monografia de conclusão de curso). UniFai, São Paulo, 2009.

BARTHES, Roland. O rumor da língua. São Paulo: Brasiliense, 1988.

O prazer do texto. 4 ed. São Paulo: Perspectiva, 1996. (Coleção Elos).

CALLIGARIS, Contardo. Para que servem as ficções? In: Folha de S.Paulo, Ilustrada, São Paulo, 18 janeiro 2007.

DELEUZE, Gilles. Conversações. São Paulo: Editora 34, 1992.

; GUATTARI, Félix. Mil platôs. vol. II. São Paulo: Editora 34, 1997.

DOSSE, François. História do estruturalismo. vol. 1. O campo do signo. Campinas: Editora da Unicamp, 1993.

ECO, Umberto. Seis passeios pelos bosques da ficção. São Paulo: Companhia das Letras, 1994.

HALL, Stuart. On postmodernism and articulation. In: MORLEY, David; CHEN, Kuan-Hsing. Stuart Hall: critical dialogues in cultural studies. Londres: Routledge, 1996. p. 131-150.

Identidade cultural na pós-modernidade. Rio e Janeiro: DP\&A, 2000.

Codificação/Decodificação. In: Da diáspora: identidades e mediações culturais. Belo Horizonte: Editora da UFMG, 2005.

MARTÍN-BARBERO, Jesus. Dos meios às mediações. Rio de Janeiro: UFRJ, 1997.

POLCHLOPECK, Silvana. O mundo pós "11 de setembro": tecendo fios/textos entre a tradução e a narratividade jornalística. (Tese de Doutorado). PGET/UFSC, Florianópolis, 2011.

PONTES, Felipe Simão; SILVA, Gislene. Acontecimento jornalístico e história. In: BENETTI, Marcia; FONSECA, Virginia P. S. Jornalismo e acontecimento: mapeamentos críticos. Florianópolis: Insular, 2010. 
SILVA, Gislene; MAIA, Flávia D. Análise de cobertura jornalística: um protocolo metodológico. In: Revista Rumores, ed. 10, vol. 5, julho-dezembro 2011.

; SOARES, Rosana de Lima. Da necessidade e da vontade de se consumir notícia. In: Comunicação, Mídia e Consumo, vol. 8, 2011, p. 181-198.

SOARES, Rosana de Lima. Pequeno inventário de narrativas midiáticas: verdade e ficção em discursos audiovisuais. In: Significação - Revista de Cultura Audiovisual. ed. 34, julho-dezembro 2010, p. 55-72.

. De convergências e hibridismos: remixagens e pilhagens em filmes de bordas. In: Revista MATRIZes, ano 5, n. 1, julho-dezembro, 2011, p. 137-154.

SOUSA, Jorge P. Teorias da notícia e do jornalismo. Chapecó: UniChapecó/Argos, 2002.

TRAQUINA, Nelson. Teorias do jornalismo: porque as notícias são como são. vol. 1. Florianópolis: Insular, 2004.

WINCH, Samuel P. Mapping the cultural space of journalism: how journalists distinguish news from entertainment. Westport/London: Praeger, 1997.

ZIPSER, Meta E. Do fato à reportagem: as diferenças de enfoque e a tradução como representação cultural. (Tese de Doutorado). FFLCH/USP, São Paulo, 2002.

; POLCHLOPEK, Silvana A. Do fato à reportagem: o ambiente da tradução jornalística. In: Revista DitoEfeito, vol. 1, 2009, p. 1-15.

. Traduzindo notícias: as possibilidades da tradução em meio jornalístico. In: Revista Inventário. vol. 6, 2007, p. 1-18. 